\title{
Functional consequences of DECTIN-1 early stop codon polymorphism Y238X in rheumatoid arthritis
}

\author{
Theo S Plantinga ${ }^{1,2}$, Jaap Fransen ${ }^{3}$, Nozomi Takahashi ${ }^{4,5,6}$, Rinke Stienstra ${ }^{1,2}$, Piet $L$ van Riel ${ }^{3}$,
} Wim B van den Berg ${ }^{4}$, Mihai G Netea ${ }^{1,2}$, Leo AB Joosten ${ }^{1,2^{*}}$

\begin{abstract}
Introduction: Dectin-1, a pattern recognition receptor expressed by the innate immune system, is known to be a major receptor inducing Th17-type adaptive immune responses that have been demonstrated to mediate autoimmunity. In this study, dectin-1 mRNA and protein expression, as well as the recently characterized DECTIN-1 Y238X early stop codon polymorphism, were studied in relation to rheumatoid arthritis (RA) susceptibility and severity.

Methods: Dectin-1 mRNA expression was measured in synovial tissue specimens of RA, osteoarthritis (OA), and nonrheumatic patients. Dectin-1 protein expression and localization were assessed in RA synovial tissue specimens. Macrophages from individuals with different DECTIN-1 genotypes were examined for differences in cytokine responses on dectin-1 stimulation. Furthermore, clinical parameters of inflammation and bone destruction of 262 RA patients were correlated with the presence of the DECTIN-1 Y238X polymorphism.

Results: Evaluation of dectin-1 mRNA expression in synovial tissue biopsies revealed an increased expression in RA specimens, compared with biopsies from OA and nonrheumatic patients. Accordingly, dectin-1 protein expression in RA synovial tissue biopsies was moderate to high, especially on macrophage-like cells. Cytokine production capacity of macrophages bearing the DECTIN-1 Y238X polymorphism was demonstrated to be impaired on dectin1 stimulation. However, the presence of the DECTIN-1 Y238X polymorphism was not associated with RA susceptibility or disease severity.

Conclusions: Although expression of dectin-1 was high in synovial tissue of RA patients, and reduced cytokine production was observed in macrophages of individuals bearing the DECTIN-1 Y238X polymorphism, loss of one functional allele of DECTIN-1 is not associated with either susceptibility to or severity of RA.
\end{abstract}

\section{Introduction}

Rheumatoid arthritis (RA) is a chronic inflammatory disorder that results in severe cartilage damage and bone destruction in synovial joints. Despite unclear disease etiology, it is commonly appreciated that both genetic and environmental factors are underlying risk factors in the pathogenesis of RA. In recent years, an important role for innate immune receptors in RA has emerged, especially focused on members of the Toll-like receptor (TLR) family $[1,2]$. These innate responses

\footnotetext{
* Correspondence: l.joosten@aig.umcn.nl

1 Department of Medicine, Radboud University Nijmegen Medical Centre, P.O. Box 9101, 6500 HB Nijmegen, The Netherlands
}

were recently suggested to modulate and induce the autoimmune-related Th17 responses [3,4].

A different class of innate immune receptors involved in microbial recognition and subsequent immune signalling are C-type lectins, of which dectin-1 is one of the most well characterized members. After its discovery as a receptor for fungal-derived 1,3- $\beta$-glucans [5], its intracellular signalling has been demonstrated to be mediated by Raf- 1 and Syk-CARD9 dependent pathways to induce production of pro-inflammatory cytokines and reactive oxygen species [6-10]. Other studies have uncovered that dectin-1 converges with TLR signalling $[11,12]$ for the induction of cytokine responses and is able to
C Biomed Central 
promote Th17 and cytotoxic T-cell responses through activation of dendritic cells $[13,14]$. It has been well established that fungal particles, either intact yeast or fungal cell wall components that can be recognized by dectin-1, such as zymosan, can act as adjuvants in several experimental models of RA [15-19]. In addition, a study by Yoshitomi and colleagues [20] revealed that $\beta$ glucan induced autoimmune arthritis in genetically susceptible SKG mice could be prevented by blocking the dectin-1 receptor.

These studies imply that dectin-1 plays a pivotal role in the innate immune system and is able to modulate adaptive immune responses, of which, especially Th17 responses are implicated in immunopathology. Furthermore, dectin-1 is involved in the induction of arthritis in mouse models through induction of intracellular signalling on recognition of fungal components. As a consequence, dectin-1 mediated inflammatory responses could contribute to the aetiology or disease severity of RA.

Recently we characterized an early stop codon polymorphism Y238X (c.714T>G, rs16910526) in DECTIN-1 [21], which was demonstrated to result in a complete loss of function of the protein. Cytokine production capacity of peripheral blood mononuclear cells (PBMCs) from individuals homozygous for the DECTIN-1 Y238X polymorphism on $\beta$-glucan or Candida albicans exposure are impaired, including TNF- $\alpha$, interleukin (IL-) $1 \beta$, IL-6, and IL-17 responses. In the same stimulation assays, individuals heterozygous for the DECTIN-1 Y238X polymorphism exhibited intermediate cytokine responses compared with wild-type individuals [22].

Considering both the involvement of dectin-1 in proinflammatory responses and the significant consequences of the Y238X polymorphism for dectin-1 function, it is compelling to assess whether dectin-1 and the DECTIN-1 Y238X polymorphism play a role in the pathogenesis or disease severity of RA. In the present study, mRNA expression of dectin-1 was assessed in synovial tissue biopsies obtained from RA patients and compared with synovial tissue specimens from osteoarthritis (OA) patients and from patients with other underlying joint pathology not related to RA. In addition, dectin-1 protein expression was assessed in tissue sections of synovial lesions obtained from RA patients. The functional consequences of the presence of the DECTIN-1 Y238X polymorphism on cytokine production capacity of macrophages were studied by stimulating the cells with $\beta$-glucans. Furthermore, the presence of the DECTIN-1 Y238X polymorphism was correlated with disease susceptibility in a cohort of 262 RA patients, and within this cohort, clinical parameters of joint inflammation and bone destruction were compared after stratifying for the DECTIN-1 genotype.

\section{Materials and methods Patients}

For assessing the effect of the DECTIN-1 Y238X polymorphism on the disease course, patient data were used from the early RA inception cohort at our clinic, described in more detail elsewhere [23]. Patients were included in this cohort if they fulfilled the ACR (American College of Rheumatology) classification criteria for RA, were at least 18 years old, had a disease duration not exceeding 1 year, and did not use DMARDs or biologic response modifiers. Age, gender, and IgM rheumatoid factor were determined at baseline. At baseline and every 3 months thereafter, patients were assessed by specialized research nurses who assigned joint inflammation scores and drew a blood sample for determination of the erythrocyte sedimentation rate. The patients indicated their global disease activity on a Visual Analogue Scale. These data were used to calculate the disease activity score (DAS28) according to the original formula [24]. Radiographs of the hand and feet were made at baseline, year 1, 2, and 3, and every third year thereafter. Radiographs of hands and feet were read in chronologic order by one of four raters, according to the Ratingen score by using reference pictures [25]. The Ratingen score (range, 0-190) is a modification of the Larsen score and evaluates joint surface destruction, graded from 0 to 5 , in 38 hand and feet joints, separately. The interrater reliability was ICC $=0.85$, tested previously with the four raters in 10 patients over 9 years. Clinical data were entered in a computerized database.

From 2006 to 2008, additional blood was collected in a convenience sample of the cohort, used for genotyping for the DECTIN-1 Y238X polymorphism. For the current study, data from cohort patients were included if a blood sample was available with a joint damage assessment at year 3 .

Consequently, 262 patients were included. The study was approved by our institutional review board, and informed consent of the patients was obtained before enrollment. The study was performed according to the principles of the Declaration of Helsinki.

\section{RNA isolation from synovial tissue}

Synovial tissue samples of RA, OA, and nonrheumatic patients were dissected during surgery or by fine needle arthroscopy under camera supervision. The tissue samples were stored at a tissue bank under liquid nitrogen until further processing. Total RNA was isolated and purified on an affinity resin (RNeasy Kit for fibrous tissues, Qiagen, Valencia, CA, USA) according to the manufacturer's instructions. Quantity and purity were assessed by using Agilent bioanalyzer (Agilent Technologies, Santa Clara, CA, USA), and integrity, by using 
nanodrop (Thermo Scientific, Waltham, MA, USA) according to the manufacturer's instructions. Total RNA was stored at $-80^{\circ} \mathrm{C}$ until further processing.

\section{Oligonucleotide array}

To measure dectin-1 mRNA expression, $100 \mathrm{ng}$ of total RNA was used as starting material for cDNA preparation. A two cycle amplification protocol was followed. Generation of biotinylated cRNA and subsequent hybridization to U133Plus 2.0 oligonucleotide arrays (Affymetrix, Santa Clara, CA, USA), washing, and staining were performed according to Affymetrix Expression Analysis Technical Manual for two cycle amplification [26]. The arrays were then scanned by using a laser scanner GeneChip ${ }^{\circ}$ Scanner (Affymetrix) and analyzed by using Affymetrix GeneChip Operating Software (GCOS version 1.4) according to the manufacturer's instructions. Array normalization and model-based calculation of expression values were performed by using DNA-Chip Analyzer (dChip) version 1.3 [27]. The Invariant Set Normalization method and the model based method were used for computing expression values [28]. These values were expressed as mean and standard error (SE).

\section{Quantitative RealTime PCR}

RNA samples were reverse transcribed by using oligo$\mathrm{dT}$ primers and MMLV reverse transcriptase. Primers were designed with Primer Express (Applied Biosystems, Foster City, CA, USA). Q-PCR was performed by using the ABI Prism 7000 sequence detection system (Applied Biosystems) for an amount of $10 \mathrm{ng}$ cDNA with SYBR Green Master mix. Quantification of the PCR signals was performed by comparing the cycle threshold value $\left(C_{t}\right)$ of the gene of interest of each sample with the $C_{t}$ values of the reference gene GAPDH $(\Delta \mathrm{Ct})$, and expressed as $2^{-\Delta \mathrm{Ct}}$ multiplied by arbitrary factor. Fold change was calculated as the mean ratio between the relative transcript levels. The sequences of primer sets used were as follows: 5'-TTCCCCATGGTGTCTGAGC3' (GAPDH forward), 5'-ATCTTCTTTTGCGTCGCCAG-3' (GAPDH reverse), 5'-TGACTCCTACCAAAGCTGTCAAAAC-3' (dectin-1 forward), and 5'TTCTCATATATAATCCAATTAGGAGGACAAG-3' (dectin-1 reverse).

\section{Immunohistochemical staining in synovial tissue}

In specimens obtained from knee surgery, dectin-1 protein expression was evaluated by immunohistochemical staining in paraffin-embedded inflamed synovial tissue sections of RA patients. The applied primary antibody was a monoclonal mouse-anti-human dectin-1 antibody (MAB 1859, purchased from R\&D Systems, Minneapolis, MN, USA), used in a concentration of $5 \mu \mathrm{g} / \mathrm{ml}$. After overnight incubation with the primary antibody, the tissue sections were incubated for $1 \mathrm{~h}$ with a secondary antibody after washing with PBS. Subsequently, the staining was visualised by applying $A B C$ complex and DAB solution. Sections were counterstained with haematoxylin. Staining with a mouse IgG2b isotype control antibody served as a negative control.

\section{In vitro macrophage stimulation assays}

PBMCs were obtained from healthy donors, either wildtype or heterozygous for the Y238X polymorphism. Cells homozygous for the DECTIN-1 Y238X polymorphism were obtained from three members of a family previously analyzed for mucocutaneous Candida infections [22]. PBMCs were isolated from peripheral blood as described previously [11]. The PBMC fraction was plated in flat-bottom 96-well plates. After $4 \mathrm{~h}$ of culture at $37^{\circ} \mathrm{C}$, cells were washed 3 times with culture medium, and the nonadherent cells were removed. The adherent monocytes were cultured for 6 days in culture medium with $10 \%$ heat-inactivated pooled human serum, until the monocytes exhibited macrophage-like morphology and expressed characteristic surface markers analyzed with flow cytometry. On day 6 of culture, after washing 3 times with fresh medium, macrophages were stimulated for $24 \mathrm{~h}$ with $\beta$-glucan $(10 \mu \mathrm{g} / \mathrm{ml})$, Pam3Cys $(10 \mu \mathrm{g} / \mathrm{ml})$, or with a combination of the two stimuli. Cytokine production was measured with ELISA (purchased from R\&D Systems) according to the guidelines of the manufacturer. Detection levels were $10 \mathrm{pg} /$ $\mathrm{ml}$ for TNF- $\alpha$ and $20 \mathrm{pg} / \mathrm{ml}$ for IL- $1 \beta$.

\section{Genotyping for DECTIN-1 Y238X polymorphism}

Genomic DNA was isolated from peripheral venous blood by using standard techniques and stored at $4^{\circ} \mathrm{C}$. Genotyping for the presence of the Y238X polymorphism in exon 6 of the DECTIN-1 gene (also known as $C L E C 7 A$ ) in the patient and in healthy control groups was performed by applying the predesigned TaqMan SNP assay C_33748481_10 on the 7300 ABI Real-Time PCR system (both from Applied Biosystems). We declare that all the subjects included in this study were prospectively asked to provide consent in regard to the use of clinical data as well as DNA samples for future investigations. All patients gave informed consent, as required by our local ethics committee and in accordance with the Declaration of Helsinki.

\section{Statistics}

Statistical analysis for the oligonucleotide array-based gene expression was performed by using dChip. The $t$ statistic was computed as (mean1 - mean2)/ $\left.\sqrt{\mathrm{SE}(\text { mean } 1)^{2}+\mathrm{SE}(\text { mean } 2)^{2}}\right)$; its value is computed based on the $t$ distribution, and the degree of freedom is set according to Welch modified two sample $t$ test [28]. 
Statistical analysis of the gene expression data obtained by quantitative PCR and of the cytokine measurements obtained with ELISA was performed by applying the Mann Whitney $U$ test.

Concerning the correlation of the DECTIN-1 genotype with clinical RA parameters, the following statistical tests were applied. Between-group differences between DECTIN-1 wild-type and heterozygous patients were analyzed by using a $\chi^{2}$ test, a $t$ test or a Wilcoxon test, as appropriate. To test the effect of the DECTIN-1 genotype on the progression of joint damage, for every patient, the annual joint-damage progression rate was calculated by subtracting the last available joint damage score from the baseline joint damage score, and dividing the joint damage progression by follow-up time. The difference between wild-type and heterozygous patients was tested by using a linear regression model with uptake of confounders. Regression assumptions were tested by using residual plots and predicted-versusobserved plots. The analysis was repeated by using longitudinal regression analysis (mixed models), by using all available data while correcting for repeated measurements within patients.

For all statistical analyses, a $P$ value $<0.05$ was considered significant.

\section{Results}

Dectin-1 mRNA and protein expression in synovial tissue To gain insight into the distribution and amount of dectin-1 expression in human synovial tissue, dectin-1 mRNA expression was measured in synovial tissue from RA, OA, and nonrheumatic patients with an oligonucleotide array and reevaluated with quantitative PCR. Microarray analysis revealed a 4-times elevated mRNA expression in RA synovial lesions compared with OA and nonrheumatic synovial tissues (Figure 1a). These findings were confirmed with quantitative PCR (Figure 1b). Furthermore, synovial biopsies from RA patients were immunohistochemically stained for dectin-1 protein expression. Dectin-1 protein appeared to be moderately to highly expressed in RA lesions and was preferentially expressed on the membranes of macrophage-like cells that infiltrated into the synovial tissue, which were present in the synovial sublining and in close proximity to blood vessels (Figure 2).

\section{In vitro macrophage stimulation assays}

Because especially macrophages are known to express dectin-1 in high amounts and are possibly involved in RA pathogenesis, we analyzed the functional consequences of the DECTIN-1 Y238X polymorphism for the inflammatory response of these cells with dectin-1 stimulation. Monocytes were differentiated into macrophages in vitro and were stimulated for 24 hours with $\beta$-glucan, the
TLR2 agonist Pam3Cys, and both ligands simultaneously. After stimulation with $\beta$-glucan, cytokine measurements revealed a diminished TNF- $\alpha$ and IL-1 $\beta$ production capacity in cells from individuals homozygous for the Y238X polymorphism compared with cells from wildtype individuals. In cells from heterozygous individuals, these responses were intermediate. Moreover, the previously described synergy between dectin-1 and TLR2 induced responses $[11,12]$ regarding TNF- $\alpha$ and IL-1 $\beta$ production was abolished in cells isolated from individuals with the polymorphism. The TLR2/dectin-1 synergism was reduced in cells isolated from heterozygous individuals and was completely absent in cells obtained from individuals homozygous for the Y238X polymorphism compared with the individuals bearing only the wildtype DECTIN-1 allele (Figure 3).

\section{Genotyping of RA patients compared with healthy controls}

To assess whether the DECTIN-1 Y238X polymorphism is associated with an altered susceptibility to RA, a cohort of 262 RA patients and a cohort of healthy individuals ( $\mathrm{n}$ $=284$ ) were screened for the presence of the polymorphism. The allele frequency of the polymorphism was $7.8 \%$ in the RA cohort, compared with $7.6 \%$ in the cohort of healthy individuals $(P=0.87)$. All individuals bearing the polymorphism were heterozygous (Table 1 ).

\section{Effects of DECTIN-1 genotype on clinical parameters of rheumatoid arthritis}

The clinical data of the 262 cohort patients are shown in Table 2. At the different time points, no differences were seen in joint damage and a tendency for higher DAS28 values between the patients with a heterozygous or wildtype DECTIN-1 genotype. Follow-up time was similar in both genotype groups; $50 \%$ were followed up for 9 years, whereas $70 \%$ were followed up for at least 6 years. The mean annual joint damage progression rate was 3.33 per year in patients bearing the wild-type DECTIN-1 compared with 3.38 per year in patients heterozygous for the DECTIN-1 Y238X allele. The uncorrected between-group difference was nearly zero, with an estimated mean annual joint damage progression of 0.05 with $P=0.95$ (Table 3). When corrected for joint damage at baseline, rheumatoid factor positivity, and the average DAS28 as possible confounders, the between-group difference remained insignificant $(P=0.57)$. Regression assumptions were met. The results of the longitudinal regression analysis (mixed models) were not different (not shown).

\section{Discussion}

Rheumatoid arthritis (RA) is a systemic, chronic inflammatory disorder with autoimmune characteristics that affects $0.5 \%$ to $1.0 \%$ of the Western population. RA 

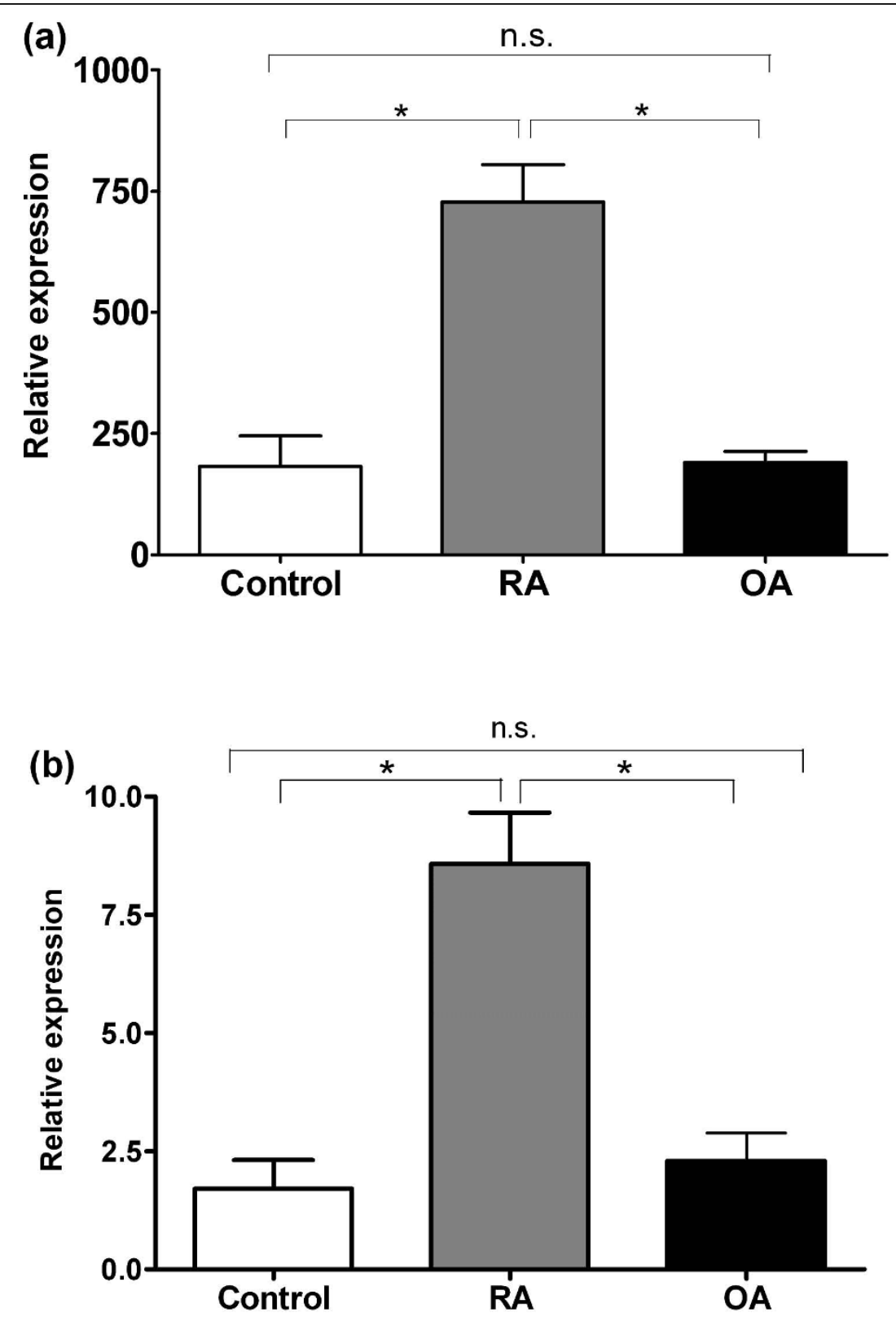

Figure 1 (a) Dectin-1 mRNA expression of human synovial tissue obtained from six nonrheumatic control individuals, 20 rheumatoid arthritis patients (RAs), and 10 osteoarthritis patients (OAs). Dectin-1 mRNA expression was analyzed with oligonucleotide array (Affymetrix system). Values represent computed expression values. (b) Confirmation of microarray data by qPCR. Data are based on four control samples, seven samples obtained from RA patients, and 6 samples from OA patients. Relative expression is depicted compared with expression of the housekeeping gene GAPDH. Data are expressed as mean \pm SD; ${ }^{*} P \leq 0.05$; n.S., not significant.

causes progressive cartilage damage and often concomitant bone destruction, which tremendously impairs joint movement. It is generally accepted that a complex interplay of genetic and environmental factors contributes to the etiology of RA.

Dectin-1, a member of the C-type lectin receptor family and the main $\beta$-glucan receptor, was recently demonstrated to be involved in promoting pro-inflammatory responses. Dectin-1 synergizes with TLR signalling pathways $[11,12]$ and contributes to induction of T-cell responses, including Th17 [14,29]. Several animal models of experimentally induced arthritis have been shown to be induced or exacerbated by administering fungal-derived particles such as zymosan and glucans that can be recognized by and signal through dectin-1. Moreover, a more specific role for dectin-1 in RA pathogenesis has been investigated in arthritis-prone SKG mice, in which $\beta$-glucan induced arthritis could be 
(a)

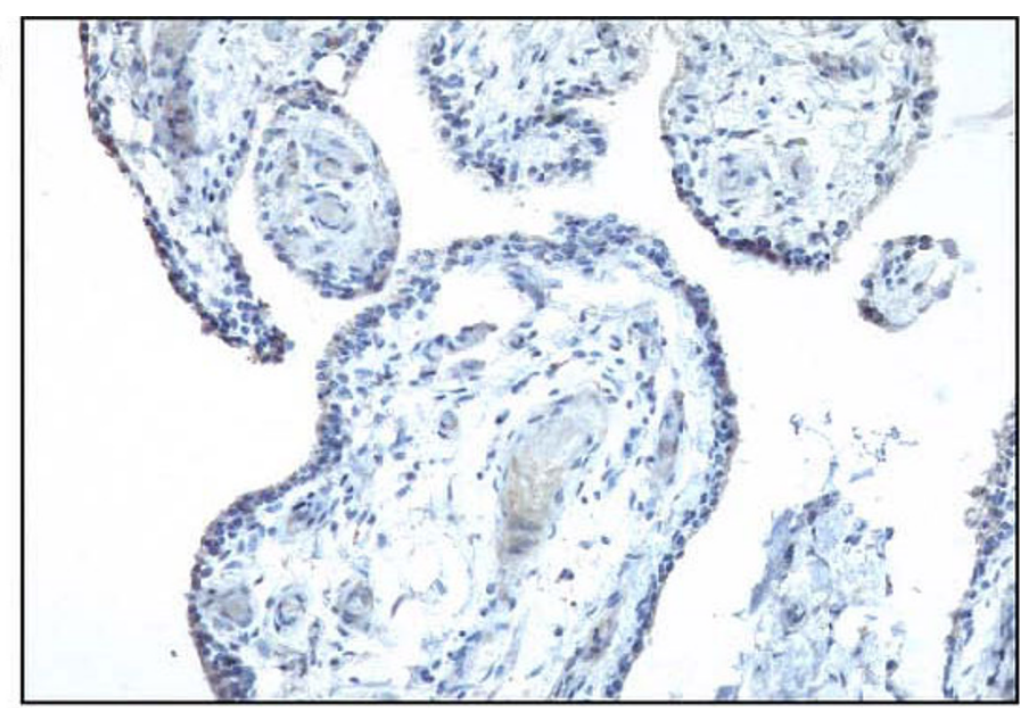

(b)

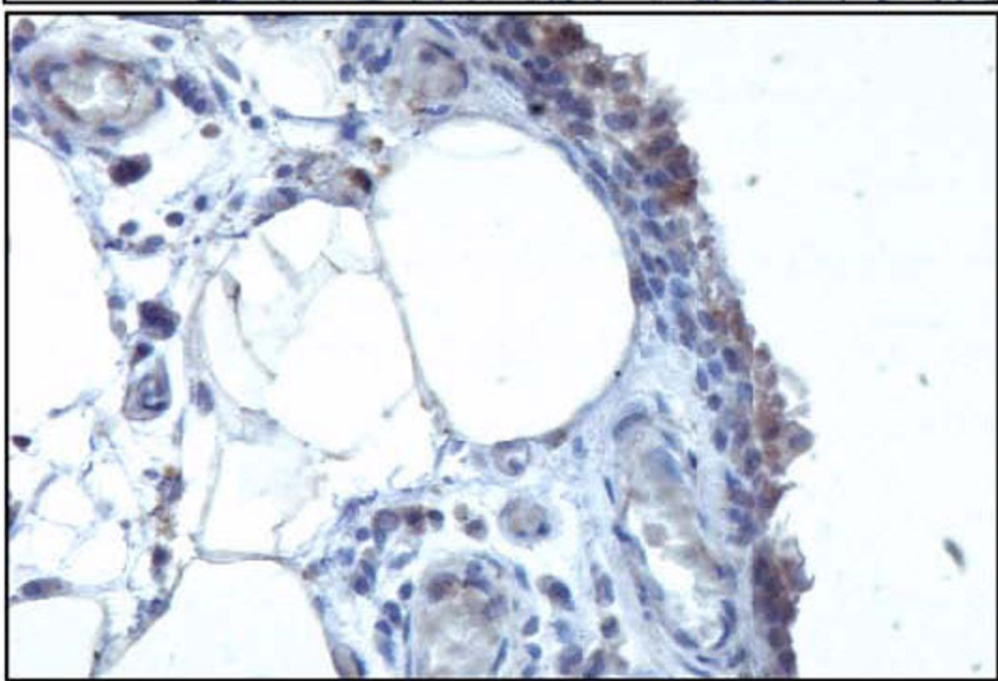

(c)

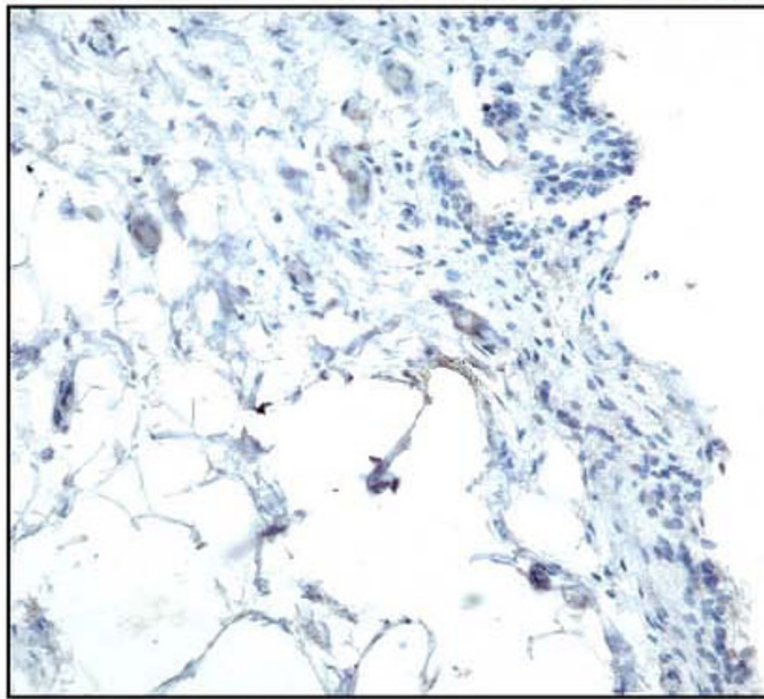

Figure 2 Immunohistochemical staining for dectin-1 on paraffin-embedded synovial tissue specimens obtained from rheumatoid arthritis (RA) patients. Pictures are representative of staining on synovial tissue biopsies from five patients. (a, b) anti-dectin-1 staining; (c) isotype control antibody. Original magnification: (a and c) 200x; and (b) 400x. 
(a)

TNF $\alpha$
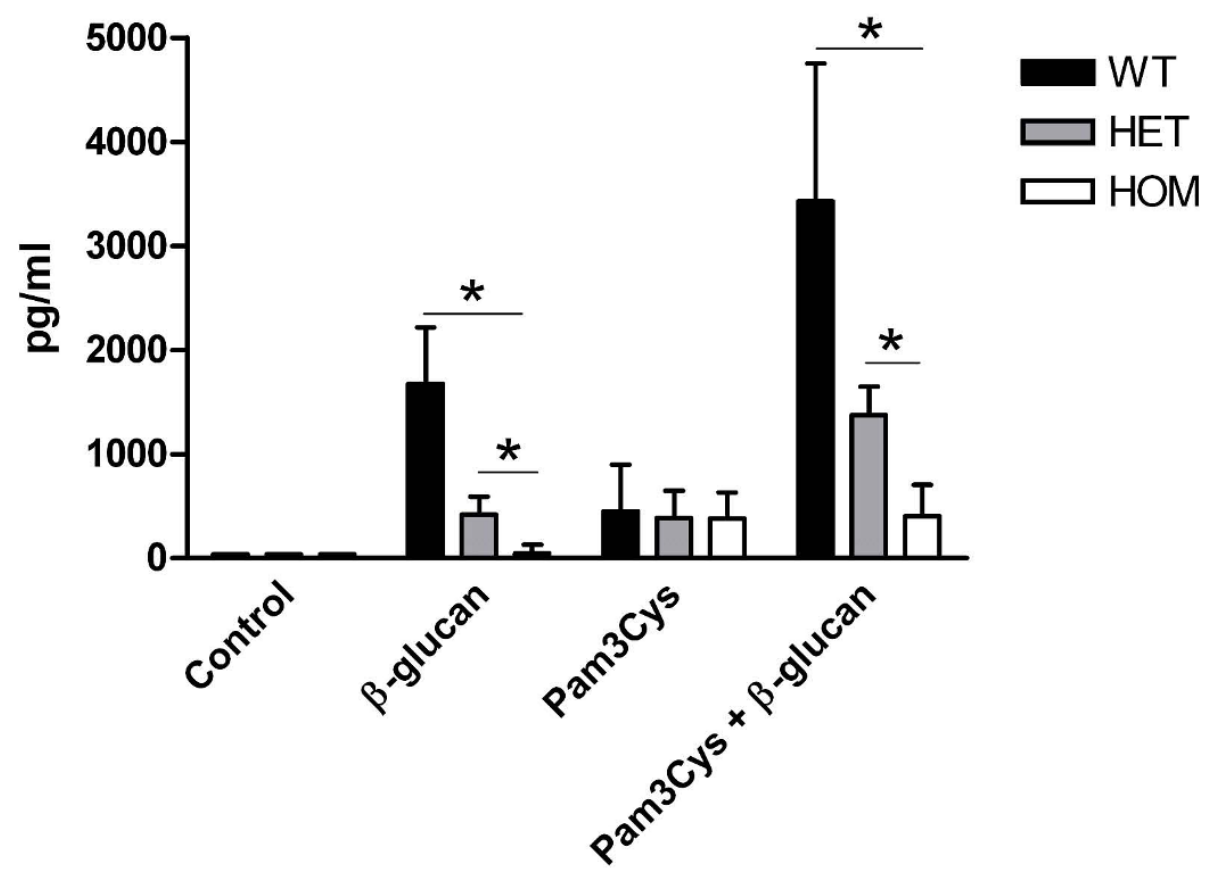

(b)

IL-1 $\beta$

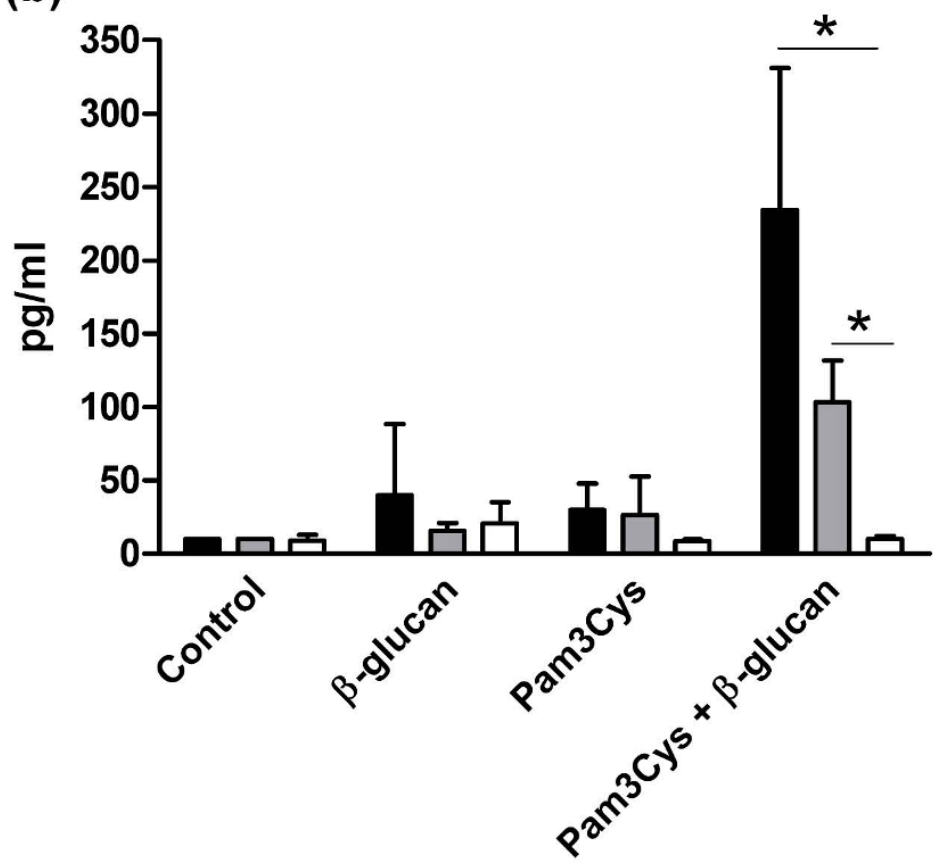

Figure 3 Cytokine production capacity of TNF- $\alpha$ (a) and IL-1 $\beta$ (b) after stimulation of monocyte derived macrophages during 24 hours with $\beta$-glucan, Pam3Cys, or $\beta$-glucan/Pam3Cys. Cells were obtained from individuals with the wild-type $(W T, n=6)$, heterozygous (HET, $n=$ 4), and homozygous ( $\mathrm{HOM}, \mathrm{n}=4$ ) for the DECTIN-1 Y238X polymorphism. Cytokine concentrations were determined with enzyme-linked immunosorbent assay (ELISA). Data are expressed as mean values \pm SD, ${ }^{*} P \leq 0.05$. 
Table 1 Genetic distribution of the DECTIN-1 Y238X polymorphism in a patient cohort of rheumatoid arthritis (n = $262)$ and in a group of healthy controls $(n=284)$

\begin{tabular}{llllll}
\hline & DECTIN-1 genotype & & \multicolumn{2}{l}{ Allele frequency } \\
\hline Cohort & Wild-type & Heterozygous & Homozygous & Wild-type & Derived \\
\hline RA $(n=262)$ & $84.4 \%(221)$ & $15.6 \%(41)$ & 0 & $92.2 \%$ & $7.8 \%$ \\
Controls $(n=284)$ & $84.9 \%(241)$ & $15.1 \%(43)$ & 0 & $92.4 \%$ & $7.6 \%$ \\
\hline
\end{tabular}

RA: rheumatoid arthritis.

Table 2 Joint inflammation and bone destruction

\begin{tabular}{llllll}
\hline Variable & $\boldsymbol{n}$ & $\begin{array}{l}\text { Homozygous wild-type } \\
\text { for DECTIN-1 }\end{array}$ & $\boldsymbol{n}$ & $\begin{array}{l}\text { Heterozygous for } \\
\text { DECTIN-1 Y238X }\end{array}$ & $\begin{array}{c}\boldsymbol{P} \text { value } \\
\text { Age (years) }\end{array}$ \\
Female & 221 & $53(14)$ & 41 & $53(13)$ & 0.87 \\
Rheumatoid factor + & 221 & $147(66 \%)$ & 41 & $25(61 \%)$ & 0.49 \\
DAS28 baseline & 220 & $163(74 \%)$ & 41 & $34(83 \%)$ & 0.23 \\
Average DAS28 year 0-3 & 212 & $5.2(1.5)$ & 40 & $5.3(1.4)$ & 0.55 \\
Average DAS28 year 4-6 & 214 & $3.9(1.1)$ & 41 & $4.1(1.2)$ & 0.37 \\
Average DAS28 year 7-9 & 203 & $3.5(1.1)$ & 35 & $3.9(1.3)$ & 0.05 \\
Joint-damage score baseline & 166 & $3.5(1.2)$ & 28 & $4.0(1.3)$ & 0.07 \\
Joint-damage score year 3 & 221 & $0(0-2)$ & 41 & $0(0-3)$ & 0.87 \\
Joint-damage score year 6 & 221 & $6(1-15)$ & 41 & $5(0-18)$ & 0.70 \\
Joint-damage score year 9 & 154 & $13(2-26)$ & 29 & $14(3-26)$ & 0.98 \\
\hline DAS28: Dis) & $20(8-35)$ & 24 & $20(3-37)$ & 0.98 \\
\hline
\end{tabular}

DAS28: Disease Activity Score using 28 joint counts. Baseline and follow-up values of disease markers of joint inflammation and bone destruction of 262 RA patients, stratified by DECTIN-1 genotype. Values are numbers (percentage), medians (p25-p75) or means (SD), as indicated by the notation.

Table 3 Between-group differences for DECTIN-1 Y238X genotype in joint-damage progression

\begin{tabular}{llll}
\hline Parameter & Estimate & SE & $P$ value \\
\hline Intercept & 3.32 & 0.32 & $<0.0001$ \\
DECTIN-1 genotype & 0.05 & 0.79 & 0.95 \\
\hline Intercept & 1.07 & 0.58 & 0.065 \\
DECTIN-1 genotype & -0.40 & 0.71 & 0.57 \\
Joint damage at baseline & 2.65 & 0.53 & $<0.0001$ \\
Rheumatoid factor + & 1.28 & 0.63 & 0.043 \\
Average DAS28 & 1.26 & 0.24 & $<0.0001$ \\
\hline
\end{tabular}

DAS28: Disease Activity Score using 28 joint counts. Results of the linear regression model with 262 RA patients. The upper model tests the difference in annual joint-damage progression rate between wild-type patients and patients heterozygous for the DECTIN-1 Y238X polymorphism, indicated by the estimate of DECTIN-1 genotype $(P=0.95)$. The lower model tests the same $(P=0.57)$, with addition of baseline joint damage, rheumatoid factor positivity, and the time-averaged DAS28 as confounders. ${ }^{a}$ Time-averaged DAS28 was centered.

prevented by competitively blocking the dectin- 1 receptor [20].

Very recently, the functional consequences of the Y238X early stop codon polymorphism in DECTIN-1 have been studied in detail. This polymorphism was demonstrated to result in a complete loss of function of the protein to bind $\beta$-glucan, and, as a consequence, cells homozygous for this polymorphism are unable to induce intracellular signalling and subsequent cytokine production on exposure to $\beta$-glucans $[21,22]$.

In this study, dectin-1 and the DECTIN-1 polymorphism Y238X (c.714T > G, rs16910526) were examined concerning their role in RA pathogenesis. Dectin-1 mRNA expression was measured with an oligonucleotide expression array and confirmed with quantitative PCR in synovial tissue biopsies from RA patients and compared with OA and nonrheumatic synovial tissue. Dectin-1 mRNA expression was fourfold higher in RA synovial tissue, compared with synovial tissues obtained from OA, in which immune mechanisms are minimally involved, and from nonrheumatic patients. Dectin-1 protein expression in RA synovial tissue was shown to be moderate to high, mostly located on infiltrating macrophage-like cells residing in the synovial sublining and around blood vessels. This indicates that dectin- 1 is present in high amounts in RA synovial tissue and therefore can contribute to the inflammatory response exerted by macrophages in this setting.

Subsequently, because dectin-1 appeared to be highly expressed on infiltrating macrophages, the consequences of the DECTIN-1 Y238X polymorphism for dectin-1 mediated cytokine production capacity of macrophages were studied. Macrophages from individuals bearing the DECTIN-1 polymorphism exhibited an impaired capacity to produce cytokines induced by dectin-1 signalling. 
This was demonstrated for TNF- $\alpha$ and IL- $1 \beta$, both crucial cytokines in RA pathogenesis [30,31].

Considering the important consequences for the function of the protein, we analyzed whether the presence of the DECTIN-1 Y238X polymorphism is correlated with the susceptibility to and clinical severity of RA in a Dutch cohort of 262 RA patients. An overall allele frequency of $7.8 \%$ was obtained and was not significantly different compared with that in a healthy control group $(\mathrm{n}=284)$ with an allele frequency of $7.6 \%(P=0.87$; Table 1). All individuals tested were heterozygous for the polymorphism. The correlation of clinical parameters, that is, inflammation markers and degree of bone destruction, also revealed no statistically significant differences (Table 2). Finding no difference in bone destruction in RA patients homozygous and heterozygous for the DECTIN-1 Y238X polymorphism could also be a problem of statistical power. However, the difference we found was nearly zero. With the group sizes we obtained, adopting a two-sided alpha of 0.05 , a "power" of 0.80, and an SD of 3 in the usual power calculation formula, we would have been able to detect a difference in annual joint damage progression in a Ratingen score of 1.5 , which we regard as reasonably small.

\section{Conclusions}

These data imply that, despite the lower cytokine responses exhibited by individuals heterozygous for the DECTIN-1 Y238X polymorphism on stimulation with dectin-1, partial dectin-1 deficiency has a major influence neither on disease susceptibility nor on the degree of inflammation and bone destruction in RA patients. Whether homozygosity for the DECTIN-1 Y238X polymorphism may result in a different susceptibility to RA remains to be investigated in studies large enough to identify the rare homozygous individuals.

\section{Abbreviations \\ ELISA: enzyme-linked immunosorbent assay; OA: osteoarthritis; PBMCs: peripheral blood mononuclear cells; RA: rheumatoid arthritis; TLR: Toll-like receptor.}

\section{Acknowledgements}

MGN was supported by a Vici grant from the Netherlands Organization for Scientific Research (NWO).

\footnotetext{
Author details

${ }^{1}$ Department of Medicine, Radboud University Nijmegen Medical Centre, P.O. Box 9101, 6500 HB Nijmegen, The Netherlands. ${ }^{2}$ Nijmegen Institute for Infection, Inflammation and Immunity (N4i), Radboud University Nijmegen Medical Centre, P.O. Box 9101, 6500 HB Nijmegen, The Netherlands. ${ }^{3}$ Department of Rheumatology, Radboud University Nijmegen Medical Centre, P.O. Box 9101, 6500 HB Nijmegen, The Netherlands. ${ }^{4}$ Rheumatology Research and Advanced Therapeutics, Radboud University Nijmegen Medical Centre, P.O. Box 9101, 6500 HB Nijmegen, The Netherlands. ${ }^{5}$ Molecular Signalling and Cell Death Unit, Department for Molecular Biomedical Research, Ghent University, VIB Research Building FSVM, Technologiepark
}

927, 9052 Ghent, Belgium. ${ }^{6}$ Department of Biomedical Molecular Biology, Ghent University, Technologiepark 927, 9052 Ghent, Belgium.

\section{Authors' contributions}

TSP, NT, and RS performed the experiments; JF performed the clinical statistical analysis; TSP, JF, PLvR, WBVdB, MGN, and LABJ designed the study and wrote the manuscript. All authors read and approved the final manuscript.

\section{Competing interests}

The authors declare that they have no competing interests.

Received: 4 August 2009 Revisions requested: 24 September 2009 Revised: 27 November 2009 Accepted: 16 February 2010 Published: 16 February 2010

\section{References}

1. Abdollahi-Roodsaz S, Joosten LA, Roelofs MF, Radstake TR, Matera G, Popa C, Meer van der JW, Netea MG, Berg van den WB: Inhibition of Tolllike receptor 4 breaks the inflammatory loop in autoimmune destructive arthritis. Arthritis Rheum 2007, 56:2957-2967.

2. Roelofs MF, Wenink MH, Brentano F, Abdollahi-Roodsaz S, OppersWalgreen B, Barrera P, van Riel PL, Joosten LA, Kyburz D, Berg van den WB, Radstake TR: Type I interferons might form the link between Toll-like receptor (TLR) 3/7 and TLR4 mediated synovial inflammation in rheumatoid arthritis (RA). Ann Rheum Dis 2009, 68:1486-1493.

3. Kattah MG, Wong MT, Yocum MD, Utz PJ: Cytokines secreted in response to Toll-like receptor ligand stimulation modulate differentiation of human Th17 cells. Arthritis Rheum 2008, 58:1619-1629.

4. Shahrara S, Huang Q, Mandelin AM, Pope RM: TH-17 cells in rheumatoid arthritis. Arthritis Res Ther 2008, 10:R93.

5. Brown GD, Gordon S: Immune recognition: a new receptor for betaglucans. Nature 2001, 413:36-37.

6. Underhill DM, Rossnagle E, Lowell CA, Simmons RM: Dectin-1 activates Syk tyrosine kinase in a dynamic subset of macrophages for reactive oxygen production. Blood 2005, 106:2543-2550.

7. Gringhuis SI, den Dunnen J, Litjens M, Vlist van der M, Wevers B, Bruijns SC, Geijtenbeek TB: Dectin-1 directs T helper cell differentiation by controlling noncanonical NF-kappaB activation through Raf-1 and Syk. Nat Immunol 2009, 10:203-213.

8. Rogers NC, Slack EC, Edwards AD, Nolte MA, Schulz O, Schweighoffer E, Williams DL, Gordon S, Tybulewicz VL, Brown GD, Reis E, Sousa C: Sykdependent cytokine induction by Dectin-1 reveals a novel pattern recognition pathway for $C$ type lectins. Immunity 2005, 22:507-517.

9. Gross O, Gewies A, Finger K, Schafer M, Sparwasser T, Peschel C, Forster I, Ruland J: Card9 controls a non-TLR signalling pathway for innate antifungal immunity. Nature 2006, 442:651-656.

10. Hara H, Ishihara C, Takeuchi A, Imanishi T, Xue L, Morris SW, Inui M, Takai T, Shibuya A, Saijo S, Iwakura Y, Ohno N, Koseki H, Yoshida H, Penninger JM, Saito T: The adaptor protein CARD9 is essential for the activation of myeloid cells through ITAM-associated and Toll-like receptors. Nat Immunol 2007, 8:619-629.

11. Ferwerda G, Meyer-Wentrup F, Kullberg BJ, Netea MG, Adema GJ: Dectin-1 synergizes with TLR2 and TLR4 for cytokine production in human primary monocytes and macrophages. Cell Microbiol 2008, 10:2058-2066.

12. Dennehy KM, Ferwerda G, Faro-Trindade I, Pyz E, Willment JA, Taylor PR, Kerrigan A, Tsoni SV, Gordon S, Meyer-Wentrup F, Adema GJ, Kullberg BJ, Schweighoffer E, Tybulewicz V, Mora-Montes HM, Gow NA, Williams DL, Netea MG, Brown GD: Syk kinase is required for collaborative cytokine production induced through Dectin-1 and Toll-like receptors. Eur J Immunol 2008, 38:500-506.

13. Gerosa F, Baldani-Guerra B, Lyakh LA, Batoni G, Esin S, Winkler-Pickett RT, Consolaro MR, De MM, Giachino D, Robbiano A, Astegiano M, Sambataro A, Kastelein RA, Carra G, Trinchieri G: Differential regulation of interleukin 12 and interleukin 23 production in human dendritic cells. J Exp Med 2008, 205:1447-1461.

14. Leibundgut-Landmann S, Gross O, Robinson MJ, Osorio F, Slack EC, Tsoni SV, Schweighoffer E, Tybulewicz V, Brown GD, Ruland J, Reis E, Sousa C: Syk- and CARD9-dependent coupling of innate immunity to the induction of T helper cells that produce interleukin 17. Nat Immunol 2007, 8:630-638. 
15. Frasnelli ME, Tarussio D, Chobaz-Peclat V, Busso N, So A: TLR2 modulates inflammation in zymosan-induced arthritis in mice. Arthritis Res Ther 2005, 7:R370-R379.

16. Hida S, Miura NN, Adachi Y, Ohno N: Cell wall beta-glucan derived from Candida albicans acts as a trigger for autoimmune arthritis in SKG mice. Biol Pharm Bull 2007, 30:1589-1592.

17. Yordanov M, Danova S, Ivanovska N: Inflammation induced by inoculation of the joint with Candida albicans. Inflammation 2004, 28:127-132.

18. Hida S, Miura NN, Adachi Y, Ohno N: Effect of Candida albicans cell wall glucan as adjuvant for induction of autoimmune arthritis in mice. $J$ Autoimmun 2005, 25:93-101.

19. Yordanov M, Tchorbanov A, Ivanovska N: Candida albicans cell-wall fraction exacerbates collagen-induced arthritis in mice. Scand I Immunol 2005, 61:301-308.

20. Yoshitomi H, Sakaguchi N, Kobayashi K, Brown GD, Tagami T, Sakihama T, Hirota K, Tanaka S, Nomura T, Miki I, Gordon S, Akira S, Nakamura T, Sakaguchi S: A role for fungal \{beta\}-glucans and their receptor Dectin-1 in the induction of autoimmune arthritis in genetically susceptible mice. J Exp Med 2005, 201:949-960.

21. Veerdonk van de FL, Marijnissen RJ, Kullberg BJ, Koenen HJ, Cheng SC, Joosten I, Berg van den WB, Williams DL, Meer van der JW, Joosten LA, Netea MG: The macrophage mannose receptor induces IL-17 in response to Candida albicans. Cell Host Microbe 2009, 5:329-340.

22. Ferwerda B, Ferwerda G, Plantinga TS, Willment JA, van Spriel AB, Venselaar H, Elbers CC, Johnson MD, Cambi A, Huysamen C, Jacobs L, Jansen T, Verheijen K, Masthoff L, Morre SA, Vriend G, Williams DL, Perfect JR, Joosten LA, Wijmenga C, Meer van der JW, Adema GJ, Kullberg BJ, Brown GD, Netea MG: Human dectin-1 deficiency and mucocutaneous fungal infections. N Engl J Med 2009, 361:1760-1767.

23. Welsing PM, van Riel PL: The Nijmegen inception cohort of early rheumatoid arthritis. J Rheumatol Supp/ 2004, 69:14-21.

24. Prevoo ML, van 't Hof MA, Kuper $H H$, van Leeuwen MA, Putte van de LB, van Riel PL: Modified disease activity scores that include twenty-eightjoint counts: development and validation in a prospective longitudinal study of patients with rheumatoid arthritis. Arthritis Rheum 1995, 38:44-48.

25. Rau R, Wassenberg S, Herborn G, Stucki G, Gebler A: A new method of scoring radiographic change in rheumatoid arthritis. J Rheumatol 1998, 25:2094-2107.

26. Lockhart DJ, Dong H, Byrne MC, Follettie MT, Gallo MV, Chee MS, Mittmann M, Wang C, Kobayashi M, Horton H, Brown EL: Expression monitoring by hybridization to high-density oligonucleotide arrays. Nat Biotechnol 1996, 14:1675-1680.

27. dChip Software. http://www.dchip.org.

28. Li C, Wong WH: Model-based analysis of oligonucleotide arrays: expression index computation and outlier detection. Proc Natl Acad Sci USA 2001, 98:31-36.

29. Osorio F, Leibundgut-Landmann S, Lochner M, Lahl K, Sparwasser T, Eberl G, Reis E, Sousa C: DC activated via dectin-1 convert Treg into IL-17 producers. Eur J Immunol 2008, 38:3274-3281.

30. Joosten LA, Helsen MM, Saxne T, Loo van De FA, Heinegard D, Berg van den WB: IL-1 alpha beta blockade prevents cartilage and bone destruction in murine type II collagen-induced arthritis, whereas TNFalpha blockade only ameliorates joint inflammation. J Immunol 1999, 163:5049-5055.

31. Zwerina J, Redlich K, Polzer K, Joosten L, Kronke G, Distler J, Hess A, Pundt N, Pap T, Hoffmann O, Gasser J, Scheinecker C, Smolen JS, van den BW, Schett G: TNF-induced structural joint damage is mediated by IL-1. Proc Natl Acad Sci USA 2007, 104:11742-11747.

doi:10.1186/ar2933

Cite this article as: Plantinga et al:: Functional consequences of DECTIN1 early stop codon polymorphism Y238X in rheumatoid arthritis. Arthritis Research \& Therapy 2010 12:R26.

\section{Submit your next manuscript to BioMed Central and take full advantage of:}

- Convenient online submission

- Thorough peer review

- No space constraints or color figure charges

- Immediate publication on acceptance

- Inclusion in PubMed, CAS, Scopus and Google Scholar

- Research which is freely available for redistribution

Submit your manuscript at www.biomedcentral.com/submit
C Biomed Central 